\title{
PHAINÓMENON E PHANTASÍA NO CETICISMO DE SEXTO EMPÍRICO
}

\section{PHAINÓMENON AND PHANTASÍA IN THE SKEPTICISM OF SEXTUS EMPIRICUS}

\author{
Juliomar Marques Silva ${ }^{1}$ \\ (juliomarmarques@hotmail.com)
}

\begin{abstract}
RESUMO
Além de motivar a suspensão de juízo [epokhé], o cético também aceita o que aparece [phainómenon] e faz desse assentimento seu critério de ação. Nesse sentido, o conceito de phainómenon é também fundamental para o pirronismo antigo; sua definição, entretanto, está intimamente relacionada com a ideia de aparência [phantasía], o que pode gerar certa confusão com o sentido deste outro termo. A phantasía ou a aparência de algo se refere a um evento subjetivo, algo que ocorre na mente do sujeito; já o phainómenon ou a coisa mesma que aparece é um evento objetivo e independente de qualquer sujeito. Portanto, faz-se necessário delimitar de modo mais preciso os contornos de cada um desses conceitos dentro do ceticismo pirrônico. A proposta deste artigo é jogar alguma luz principalmente sobre esses dois conceitos, a saber, phainómenon e phantasía, e tentar esclarecer suas diferenças e semelhanças. Para esse propósito, tomaremos como referência principal o texto Hipotipóses pirronianas, de Sexto Empírico.
\end{abstract}

Palavras-chave: Pirronismo. Phainómenon. Phantasía. Sexto Empírico.

\begin{abstract}
The skeptic is not only someone who motivates the suspension of judgment [epokhé], but also someone that accepts what is apparent [phainómenon] and makes it their criterion for action. In this sense, the concept of phainómenon is also central in ancient Pyrrhonism; its definition, however, is closely linked to the idea of appearance [phantasía], and this could cause confusion between the terms. The phantasía or the appearence of something refers to a subjective event, something that occurs in the person's mind; the phainomenon or the very thing that appears is an objective event and is independent of any subject. Therefore, it is necessary to delimitate in a precise way the lines of each one of these concepts inside Pyrrhonian skepticism. This article intends mainly to throw some light on these two concepts, phainómenon and phantasía, and to try to make a clarification in regards to their distinctions and resemblances. For this purpose, we will take as the main reference the book Outlines of skepticism of Sextus Empíricus.
\end{abstract}

Keywords: Pyrrhonism. Phainómenon. Phantasía. Sextus Empiricus.

\footnotetext{
${ }^{1}$ Doutorando em Filosofia pela Universidade Federal da Bahia (UFBA).

CV Lattes: http://lattes.cnpq.br/1696878080795592.

ORCID: https://orcid.org/0000-0003-4966-5962.
} 


\section{DUAS OBSERVAÇÕES PRELIMINARES}

A palavra phainómenon era muito comum e muito utilizada na filosofia grega (PORCHAT, 2013). Não apenas os céticos ${ }^{2}$, mas podemos dizer que grande parte da filosofia antiga, de uma forma ou de outra, utilizou-se desse conceito, que reporta a uma discussão clássica, também comum entre os gregos, sobre o Ser [tá onta] e o Aparecer [tó phainómenon] das coisas (PORCHAT, 1991). O ser seria algo como a essência, a natureza real e absoluta, enquanto o aparecer seria aquilo que se mostra ou se manifesta para nós - aquilo que aparece é o fenômeno que se desvela para nossa experiência.

A filosofia antiga tinha por objetivo entender e explicar a natureza das coisas; o discurso filosófico pretendia ascender de um entendimento comum e chegar à compreensão da natureza própria, essencial e absolutas delas. Sócrates, nos diálogos platônicos, enfatizava que conhecer algo sobre alguma coisa - por exemplo, se a virtude pode ser ensinada - demandava antes de tudo que a pessoa fosse capaz de explicar o que aquele algo era, e isso surge como uma tarefa extremamente difícil; o que vemos são seus interlocutores falhando toda vez que tentam realizar essa tarefa (LEE, 2010, p. 15). O objeto da filosofia era o Ser [tá onta] das coisas, a natureza essencial ou o que as coisas são em si mesmas. A contraparte era o entendimento comum de como as coisas nos aparecem, e o que aparece [tó phainómenon] é aquilo que se manifesta para nós (PORCHAT, 1991, p. 125). A questão é que a aparência das coisas não diz nada sobre como as coisas são em si mesmas, não diz nada sobre sua natureza real ou sobre seu ser; a aparência diz apenas como nós percebemos as coisas. Assim, era bastante comum perguntar se existia algo para além dos fenômenos que percebemos e se era necessário entender as coisas para além da maneira como elas nos aparecem. O questionamento da filosofia antiga se dava justamente no âmbito dessa questão: as coisas se manifestam e aparecem para nós; porém, é necessário ir além e entendê-las em sua natureza real, essencial e absoluta, ou seja, em seu ser.

Essa discussão entre Ser e Aparecer estava presente em grande parte da filosofia antiga. Alguns, como Protágoras, afirmavam que a verdade é aquilo que aparece para cada um: "Não quererá ele, então, dizer que as coisas são para mim conforme me aparecem, como serão para ti segundo te aparecem?" (PLATÃO, 152a); outros, como o próprio Platão, não aceitavam essa posição e afirmavam que devemos conhecer a essência das coisas: "Nesse caso, como diremos que seja o vento em si mesmo: frio ou não frio? Ou, diremos como Protágoras, que é frio para

\footnotetext{
${ }^{2}$ Sempre que me referir ao ceticismo e ao cético, tenho em mente o ceticismo e o cético de Sexto Empírico. A ideia é não os confundir com outras formas de ceticismo, como com o ceticismo cartesiano.
} 
quem sentiu arrepio e não o é para o outro?” (PLATÃO, 152b). Podemos perceber que a noção de fenômeno ou de aparência não estava comprometida com a natureza real ou a essência das coisas, mas apenas retratava o modo como nós percebemos o mundo através de uma experiência sensível e intelectual. A noção de ser, por sua vez, pretendia expressar e demonstrar o que era a essência ou a natureza real das coisas.

Talvez pela obviedade de sentido e familiaridade com essa discussão, muitos autores antigos não se deram o trabalho de explicar o significado desses termos. Sexto Empírico, por exemplo, não apresenta uma explicação detalhada para o conceito de fenômeno, apesar de esse ser um termo de suma importância para seu ceticismo. Por outro lado, acreditamos que para o leitor de sua época não se fazia necessário oferecer maiores explicações para termos de sentidos tão óbvios (PORCHAT, 2013, p. 299-300). Sexto Empírico, apesar de muitas vezes fazer referência ao fenômeno, explica-o muito sucintamente, apenas nos pontos de maior interesse para o ceticismo pirrônico (HP I, 15, 19-20, 21-24, 49; HP II, 94; HP III, 254, 266; AM VII, 30; AM XI, 240). ${ }^{3}$

O phainómenon é aquilo que se manifesta para nós em nossa vivência cotidiana principalmente por quatro vias: como guia da natureza, pelas necessidades das afecções, pela manutenção das leis e dos costumes e também pelo aprendizado das artes ou dos ofícios (HP I, 23-24). A noção de fenômeno no ceticismo, então, só pode ser bem compreendida por meio de um entendimento geral dos textos de Sexto Empírico. Somente observando as passagens mais importantes de seus textos, nas quais ele cita o phainómenon, podemos formar uma compreensão mais adequada desse conceito, que é sem dúvidas um dos mais relevantes ao pirronismo.

Outro ponto a ser esclarecido previamente é que a tradução da palavra grega phainómenon foi fator de grande discussão entre os estudiosos do pirronismo. Muitos autores traduziram o termo phainómenon por aparência, como é o caso da tradução clássica de Bury: “o cético, para não permanecer inteiramente inerte e sem ação nas atividades do dia a dia, deve possuir um critério de escolha e aversão, a saber, as aparências" (AM VII, 30; cf. HP I, 22); traduções mais recentes, porém, optaram por traduzir phainómenon por o que aparece - é o caso de Porchat (2013, p. 303) e também da célebre tradução de Annas e Barnes: “dizemos, então, que o critério cético é o que aparece" (HP I, 22). Esses detalhes de tradução são

\footnotetext{
${ }^{3}$ A obra de Sexto Empírico é tradicionalmente citada a partir das siglas HP para as Hipotipóses pirronianas e AM para Contra os matemáticos. A numeração romana refere-se ao livro da obra citada e algarismos arábicos, ao parágrafo em questão.

${ }^{4}$ No caso de Bury, phainómenon é traduzido por "the appearance"; já em Annas e Barnes, é traduzido por "what is apparent".
} 
relevantes porque fazem toda a diferença no sentido e na interpretação do conceito de fenômeno no ceticismo de Sexto Empírico.

A tradução de phainómenon por "aparência" pode causar confusão com phantasía, conceito também importante para o entendimento da noção de fenômeno no ceticismo pirrônico. A fantasia refere-se a um evento mental (HP II, 70) ou algo que ocorre na mente do sujeito: a percepção dos objetos causa em nós uma impressão, gerando uma imagem ou uma representação daquele objeto em nossa mente, e essa fantasia ou aparição mental é subjetiva e dependente do sujeito. Bury traduz phantasía por "representação": "nem sentidos nem intelecto estariam conscientes das coisas sem a representação" (AM VII, 370); já Annas e Barnes traduzem phantasía por "aparência": "mesmo se concebermos que as aparências são apreendidas, as coisas não podem ser julgadas em virtude delas" (HP II, 72). Ao traduzirmos phainómenon por "aparência", como faz Bury, seu sentido se assimila ao sentido do termo phantasía, pois o fenômeno como aparência pode dar a ideia de algo também subjetivo e mental - essa aparência, o fenômeno, também poderia significar um evento que ocorre na mente do sujeito. Assim, o fenômeno traduzido como "aparência" pode ser confundido com o termo "fantasia"; ambos podem sugerir aspectos subjetivistas. Por outro lado, traduzir o fenômeno por "o que aparece", como fazem Annas e Barnes, traz um sentido objetivo para o termo: o fenômeno é aquilo que aparece; é, portanto, objetivo e impessoal. O evento subjetivo que ocorre em nossas mentes é a fantasia, essa sim melhor traduzida por "aparência", como faz a tradução de Annas e Barnes. O phainómenon é o que aparece fora de nós e a phantasía é a aparência em nós daquele fenômeno; o primeiro é um evento objetivo e que ocorre no mundo, o segundo, um evento mental que ocorre no sujeito. Esta última interpretação parece ser mais adequada, levando-se em conta as intenções de Sexto Empírico para com o termo "fenômeno".

O fenômeno entendido como aparência, como dissemos acima, causa confusão com o termo "fantasia", e isso pode nos levar a erros graves de interpretação, uma vez que também podemos entender essa aparência - ou fenômeno, assim traduzido - como possuindo um aspecto subjetivista. Por essas razões, a tradução de Annas e Barnes nos parece ser mais adequada quanto ao sentido do termo "fenômeno", marcando essa distinção em relação ao termo "fantasia". Ao traduzirmos phainómenon por "o que aparece", damos ao termo um sentido objetivo, que a nosso ver parece ser mais correto. Já phantasía podemos traduzir por "aparência", que nos traz a ideia de ser subjetiva, de ser um evento na mente do sujeito. Assim, "fenômeno" e "fantasia" apresentam maior clareza, e dificilmente confundiremos um com o outro. Por essa razão, então, daremos prioridade à tradução de Annas e Barnes, e não à de Bury. 
Após destacarmos essas diferenças de tradução e interpretação, a tarefa que propomos para este artigo é esclarecer os sentidos e os aspectos peculiares tanto do conceito de fenômeno quanto do conceito de fantasia. Pontuando as nuances de cada termo, pretendemos formar uma compreensão adequada daquilo que Sexto Empírico dizia ser uma vida cética guiada pelos fenômenos (HP I, 21-24).

\section{O ASSENTIMENTO AOS FENÔMENOS COMO UMA FASE POSITIVA DO CETICISMO PIRRÔNICO}

O ceticismo pirrônico em geral apresenta duas faces distintas. A primeira delas podemos chamar de negativa ou destrutiva; nesse momento, o cético replica as ideias e as teses dos filósofos, fazendo oposição aos argumentos dogmáticos para chegar à equipolência e à consequente suspensão de juízo [epokhé]. A segunda face do ceticismo é aquela em que, após a suspensão do juízo sobre muitas ideias dogmáticas, o cético tem de tomar decisões e fazer escolhas em seu cotidiano; esse momento podemos designar como positivo. É nele que o cético diz não ter mais crenças dogmáticas sobre como as coisas são e segue apenas o phainómenon ou o que aparece (HP I, 15, 22).

A face negativa do ceticismo é caracterizada basicamente por três elementos: a oposição, a equipolência e a suspensão de juízo. Esses elementos, podemos dizer, não apenas constituem o aspecto negativo do ceticismo, mas são os elementos que definem e constituem o próprio ceticismo. ${ }^{5}$ Sexto Empírico, no livro I das Hipotipóses, diz que o ceticismo é a habilidade de opor todas as coisas, tanto as coisas que aparecem quanto as coisas que são pensadas, e, através da equipolência, chegar à suspensão de juízo (HP I, 8). Esse é o caminho que nos leva ao ceticismo, e o cético é aquele que obtém essa habilidade de oposição e de suspensão de juízo (HP I, 11).

A ideia de oposição é global; podemos confrontar percepções sensíveis com percepções sensíveis, podemos confrontar pensamentos com pensamentos e, por fim, também podemos confrontar as percepções sensíveis com pensamentos e vice-versa. Essa ideia de oposição advém da máxima cética de que para toda afirmação ou argumento existem outras afirmações e outros argumentos conflitantes e igualmente fortes em poder de persuasão (HP I, 12, 202). Desse modo, para qualquer afirmação que se faça, seja de cunho sensível ou

\footnotetext{
${ }^{5}$ Para uma definição completa do ceticismo, acrescente-se a esses três conceitos apenas a ideia de tranquilidade ou ataraxía.
} 
intelectual, podemos opor outras afirmações que lhes sejam conflitantes, embora não menos persuasivas. A partir dessa oposição gera-se a equipolência, ou seja, em tal confronto nenhuma afirmação se mostra mais convincente e persuasiva que outra.

Digamos que estamos investigando a proposição $\mathrm{P}$, sendo $\mathrm{P}$ uma tese sobre algum conceito importante como a virtude, a justiça, o bem etc. $\mathrm{O}$ cético percebe que há razões e argumentos tanto afirmando quanto negando a verdade de P; o cético também nota que ele mesmo pode produzir essas razões e argumentos conflitantes. O trabalho ou habilidade que caracteriza o cético é justamente o de colocar em oposição essas razões e esses argumentos, tanto os que afirmam quanto os que negam a verdade de algo (HP I, 8, 10, 11). Se há boas razões para afirmar $\mathrm{P}$ e há também boas razões para negar essa proposição, estamos em equipolência a respeito da verdade de $\mathrm{P}$. A verdade de $\mathrm{P}$, nesse caso, é tão persuasiva quanto seu contrário, ou seja, sua falsidade. Assim sendo, não há como decidir para um dos lados, da verdade ou da falsidade de P; devido à equipolência, devemos então suspender o juízo sobre a proposição $P$.

Os elementos da oposição e da equipolência são pontos questionáveis da face negativa do ceticismo. Podemos objetar se é realmente possível sempre haver argumentos e afirmações conflitantes e equipolentes no que diz respeito à verdade de algo. Algumas afirmações e argumentos parecem ser praticamente incontestáveis, sendo muito mais convincentes e persuasivos que outros. Frente a um argumento suficientemente persuasivo, a oposição e a equipolência seriam impossíveis. Diante de uma afirmação persuasiva, não haveria outras afirmações conflitantes, pois, sendo aquela convincente, não podemos oferecer nenhuma outra capaz de enfraquecê-la ou de equiparar-se a seu poder de persuasão. Essa objeção nega a máxima cética de que para toda afirmação ou argumento sempre existem outras afirmações e argumentos conflitantes e igualmente persuasivos; ao contrário, ela afirma que alguns argumentos e afirmações são sempre mais convincentes e mais persuasivos que outros. Ainda assim, o cético poderia retrucar dizendo que esta última suposição é igualmente arbitrária.

De toda sorte, tal é um problema que o texto de Sexto Empírico não levanta. Para ele, toda afirmação e todo argumento são passíveis de serem confrontados com outras afirmações e outros argumentos conflitantes e igualmente persuasivos (HP I, 12, 202-203), e o passo que nos leva da equipolência à suspensão de juízo não é problemático, pois, quando não podemos decidir sobre a verdade ou falsidade de uma questão - devido à igual força persuasiva de ambos os lados -, devemos suspender o juízo sobre a questão. Para o ceticismo, portanto, toda questão acerca da verdade de algo permanece passível de oposição, de equipolência e de suspensão de juízo. 
Essa é a face do ceticismo que podemos considerar como negativa: o momento em que o cético opõe e suspende o juízo sobre a verdade das coisas. Tal aspecto negativo caracteriza não apenas uma parte, mas, podemos dizer, define e constitui o próprio ceticismo. Alguém só se torna cético ao passar por essa experiência e adquirir essa habilidade (HP I, 11). Nota-se, porém, que a oposição e a suspensão de juízo não constituem uma experiência única e pontual, sendo mais bem compreendidas como uma experiência repetida e continuada, que deve sempre ser renovada a cada vez que o cético se deparar com a pergunta sobre a verdade de algo.

Além da face negativa, há também uma face positiva no ceticismo pirrônico. Para além da oposição e da suspensão de juízo, é também necessário que o cético continue agindo e tomando decisões no dia a dia. No entanto, como escolher entre uma coisa e outra se o cético suspende o juízo sobre a verdade de todas as coisas? Depois da suspensão de juízo, o cético pode se encontrar num impasse que impossibilitaria até mesmo a ação, ou poderia, ao escolher uma coisa e não outra, ser visto como incoerente, já que as escolhas demandam crenças. ${ }^{6}$ Por essa razão, o cético se baseia no phainómenon ou naquilo que aparece (HP I, 13). Porque não pode permanecer inativo nem ser incoerente com seus princípios, o cético adota o que aparece como um guia para a ação, de acordo com as experiências de seu cotidiano (HP I, 23). Essa "crença" nos fenômenos não é incoerente, porque ela não possui implicações dogmáticas, não diz como as coisas são, mas diz apenas aquilo que aparece. Por isso, não há contradição em não ter crenças dogmáticas e, ainda assim, adotar ou crer nos fenômenos como critério de ação. Essa é uma face que podemos chamar de positiva, pois o assentimento ao phainómenon permite ao cético continuar agindo, tomando suas decisões e fazendo suas escolhas no cotidiano, sem que com isso seja incoerente com a suspensão de juízo.

A suspensão de juízo é tão importante quanto problemática para o ceticismo; realmente parece tolice sustentar a ideia de que é possível suspender o juízo sobre todas as coisas. A suspensão de juízo nada mais é que um estado mental em que estamos impossibilitados de aceitar ou rejeitar algo (HP I, 10, 196). Nesse estado, a verdade e a falsidade de uma questão se mostram igualmente persuasivas, de modo que não podemos nos inclinar para nenhuma delas e, por isso, mantemos o juízo em suspensão. Ao perceber que para cada questão existem opiniões tanto afirmativas quanto negativas e que essa disputa parece ser insuperável, o cético se vê forçado a não afirmar nem negar nada sobre a verdade das coisas, mantendo a suspensão

\footnotetext{
${ }^{6}$ Desde os estoicos essa é uma objeção feita aos pirrônicos: trata-se da conhecida crítica da apraxia ou inação direcionada contra o ceticismo. O ponto é que nossa vida cotidiana demanda crenças e não podemos agir sem crer. Se os céticos dizem não terem crenças, eles também não poderiam agir, mas se eles continuam agindo é porque têm crenças, e isso é incoerente com a posição cética.
} 
do juízo. É assim que o cético entende tal suspensão: não devemos nem afirmar nem negar nada sobre a verdade ou a natureza real das coisas. No entanto, se o cético suspende o juízo sobre a verdade de todas as coisas, não há como escolher entre uma coisa e outra, não há como tomar a mais simples decisão; consequentemente, toda ação estaria comprometida, bem como a própria vida do cético. Sexto Empírico parecia estar ciente dessa objeção e por isso, logo no início das Hipotipóses pirronianas, ele nos mostra qual é o critério adotado pelos céticos que possibilitaria a manutenção da ação após a suspensão de juízo. O critério de ação para o cético é o que aparece - em outras palavras, o phainómenon (HP I, 22; AM VII, 30).

Após a suspensão de juízo, o cético diz não ter mais crenças - porém, "crenças" a respeito de como as coisas podem ser no real. O cético não possui mais crenças sobre a natureza real das coisas, sobre como elas são, mas assente aos fenômenos ou ao que aparece (HP I, 13). O que aparece não revela a realidade nem tem implicações para com o ser ou a essência das coisas; o phainómenon apenas revela como as coisas aparecem para nossa percepção e entendimento. Dessa forma, ao aceitarem aquilo que aparece como guia para a vida cotidiana, os céticos não estão sendo incoerentes ou dogmáticos, pois o que aparece não é dogmático. ${ }^{7}$ Sendo assim, a crença naquilo que aparece permite a ação do cético sem que seja incoerente com a suspensão de juízo. O cético permanece agindo, assentindo ao phainómenon ou às coisas como elas aparecem e, ao mesmo tempo, mantém a suspensão do juízo sobre o que as coisas são em si mesmas.

Esse posicionamento do ceticismo em relação ao fenômeno - assentir ao que aparece e fazer disso um critério prático para a ação e para a conduta no dia a dia - dá ao ceticismo uma face positiva. O cético, então, não se limitaria a fazer oposição e a suspender o juízo acerca das coisas, não se limitaria a uma postura negativa. $\mathrm{O}$ assentimento aos fenômenos permite ao cético fazer escolhas, tomar decisões, praticar ações e ter uma conduta comum no cotidiano. Esse assentimento aos fenômenos dá positividade à postura cética. Não fosse a crença nos fenômenos, o cético poderia permanecer completamente inativo ou agir de modo incoerente com a suspensão de juízo; de outra perspectiva, entretanto, o ceticismo nos diz que, se a ação nos exige crenças, ao menos não exige crenças dogmáticas. O texto de Sexto Empírico é claro nesse ponto, e ele obviamente sabia de todas essas exigências e implicações; por isso, logo nos

\footnotetext{
${ }^{7}$ Uma crença dogmática tem a pretensão de dizer o Ser ou a natureza absoluta das coisas. A crença no phainómenon não tem essa pretensão; ela apenas mostra como as coisas nos aparecem. Sendo assim, uma crença naquilo que aparece não seria uma crença dogmática e, por isso, a crença cética no phainómenon não é incoerente com a suspensão de juízo.
} 
primeiros capítulos das Hipotipóses ele enfatiza o conceito de phainómenon e sua importância para a conduta do cético como critério da ação.

\section{A NOÇÃO DE PHAINÓMENON}

O phainómenon é aquilo que aparece, aquilo que é percebido e que se mostra para nossa experiência sensível e intelectual. Em outras palavras, o que aparece é o que se torna visível, o que é perceptível, o que se revela e se manifesta subitamente para nós. O mundo se mostra e se manifesta para nossa experiência; nesse sentido, o mundo é o que aparece. A noção de fenômeno, portanto, baseia-se nessa objetividade do mundo, que se mostra e se revela para nossa percepção.

Segundo Sexto Empírico, como vimos, os fenômenos se manifestam ou aparecem para nós principalmente por quatro vias: como guia da natureza, pela necessidade das afecções, pela manutenção das leis e dos costumes e pelo aprendizado das artes ou ofícios (HP I, 23). Além disso, ele diz:

Como guia da natureza, somos naturalmente dotados de percepção sensível e de intelecto; por isso, percebemos uma porção de coisas sensíveis e também intelectuais. Pela necessidade das afecções, a sede nos leva naturalmente a procurar bebida e a fome nos leva a comer, dentre outras coisas. Pela manutenção das leis e dos costumes, é comum aceitarmos o ponto de vista usual e dizermos que a piedade é um bem e a impiedade um mal. E, pelo aprendizado das artes ou ofícios, também não nos tornamos inativos neste âmbito. (HP I, 24)

Sexto Empírico deixa claro que diz tudo isso sem manter opinião sobre como essas coisas são no real, sem afirmar nada sobre a essência ou sobre a verdadeira natureza delas; porém, aceita-as todas no modo como aparecem. Essa é a diferença entre o cético e o dogmático: o cético não diz que as coisas são como aparecem - ele não negaria que o mel aparece doce, a questão é se o mel é em si doce (HP I, 20) como pretende afirmar o dogmático. O cético suspende o juízo sobre a afirmação dogmática que diz algo sobre a natureza real das coisas, sobre como elas são em si mesmas; ele suspende o juízo sobre se "o mel é realmente doce". Acima vimos a dificuldade de afirmar a verdade de uma proposição como essa, pois há conflito, oposição e equipolência de opiniões. Por isso, o cético suspende o juízo sobre se essa é uma propriedade real do mel em si, mas não suspende o juízo sobre aquilo que aparece, isto é, não nega o fato de que o mel aparece doce. 
Nossa percepção do fenômeno é composta tanto por nossa experiência sensitiva quanto por nossa experiência racional ou intelectual (PORCHAT, 1991, p. 123). A experiência sensitiva dos objetos, das cores, da luz etc. nos mostra os fenômenos que aparecem para nossa percepção sensível. Assim como, "pela necessidade das afecções, a fome nos leva à comida e a sede à bebida" (HP I, 24), também pela necessidade das afecções percebemos todas aquelas coisas, todas elas aparecem para nossa sensibilidade. $\mathrm{O}$ mesmo acontece com nossa experiência intelectual. Nossa experiência racional da forma, da proporção, da durabilidade dos objetos, bem como dos conceitos, dos argumentos, das lembranças etc. nos mostra o que aparece para nossa razão e entendimento. O que aparece é também racional e intelectual, como nos diz Sexto sobre "a manutenção das leis e dos costumes" e "o aprendizado das artes ou dos ofícios" (HP I, 24). O phainómenon ou o que aparece, portanto, é aquilo que se manifesta e se mostra para nossa experiência sensível e racional; por isso, percebemos fenômenos sensíveis e fenômenos racionais ou intelectuais. Vejo algumas cadeiras, uma mesa, um computador, papéis, livros etc. Essas coisas percebo através dos sentidos. Além delas, percebo também determinada temperatura, luz, odor e muitas outras coisas, também pelos sentidos. Tudo isso é o que aparece para minha percepção sensível, tudo isso constitui o fenômeno sensível que me aparece neste momento. Além desse tipo de experiência, tenho também um tipo de experiência intelectual: percebo que cada objeto apresenta uma forma específica, uma proporção em relação aos outros, que alguns duram mais que outros etc. Essa experiência não tenho pelos sentidos, mas pelo intelecto ou entendimento. Também percebo muitas lembranças, pensamentos, raciocínios, argumentos e conceitos; recordo que fui criado numa cidade distante daqui, numa casa onde moram meus pais, que naquela casa ainda tenho um quarto, que esse quarto provavelmente deve estar fechado neste momento etc. Todas essas coisas percebo não através de meus sentidos, mas através de meu intelecto e de meu entendimento. Assim, todas essas coisas que percebo intelectualmente - toda essa experiência racional - também constituem o fenômeno inteligível ou intelectual que me aparece neste momento. Percebem-se, portanto, muitos fenômenos sensíveis e também muitos fenômenos racionais e intelectuais.

Acessamos o que aparece através de nossas afecções, isto é, de nossas impressões. O fenômeno causa em nós uma afecção, afeta-nos na medida em que aparece para nós. Essas afecções, impressões ou sensações causadas em nós pelos fenômenos são o que Sexto Empírico chamava páthos e, em sentido oposto, através dessas mesmas afecções é que podemos perceber e distinguir aquilo que aparece. Nossas afecções são sensíveis e intelectuais; portanto, o páthos apontado por Sexto não é apenas sensível, é também intelectual. 
Uma afecção é o resultado do contato de nossa sensibilidade ou de nosso intelecto com as coisas do mundo; o fato de sermos afetados pelas coisas nos provoca uma afecção, uma sensação ou uma impressão. Em outras palavras, a afecção é um estado subjetivo causado por algo objetivo. Se ficar diante de duas bolas de mesmo tamanho, uma verde e outra vermelha, cada uma delas me afetará de modo distinto, provocando em mim suas afecções e impressões específicas; cada uma delas me afetará de um modo específico e, por isso, poderei distingui-las como sendo uma verde e outra vermelha. O cético, ao relatar aquilo que aparece, nada mais faz do que dizer aquilo que lhe afeta, ou seja, ele diz quais são suas próprias afecções (HP I, 15), e o que aparece pode causar-lhe tanto impressões sensíveis quanto impressões intelectuais. Por meio dessas impressões ou afecções é que se pode perceber e expressar o phainómenon.

O phainómenon simplesmente aparece e nos afeta a cada instante. Isso é bastante claro com os fenômenos sensíveis, mas ocorre também com os fenômenos intelectuais. Nossa própria experiência sensível é impregnada de elementos racionais, pois, no momento em que percebemos algo sensível, como a cor e a textura de um objeto, percebemos também suas características racionais, sua forma e sua durabilidade. O computador que está em minha frente neste momento provoca em mim a afecção e a impressão desse objeto; recebo impressões sensíveis sobre sua cor, textura e odor, mas recebo também impressões intelectuais, como a ideia de sua durabilidade, de sua forma, de sua proporção em relação a outros objetos na mesa etc. Estas últimas afecções também são causadas em mim pelo objeto computador, porém são impressões intelectuais e racionais. O objeto que aparece causa em mim uma afecção [páthos], provocando tanto impressões sensíveis quanto intelectuais. Pela mesma via, agora no sentido oposto, através dessas afecções e desse páthos tenho a percepção desse objeto que me aparece.

As afecções sensíveis apresentam caráter "passivo e involuntário" (HP I, 22). Independentemente de minha vontade, o que aparece causa em mim as afecções sensíveis que lhes são peculiares. Não posso deixar de perceber as cores, odores, texturas, sons e sabores dos objetos. Todas essas afecções sensitivas são passivas, involuntárias e irrecusáveis. Dentre as afecções intelectuais, algumas são também passivas e involuntárias; outras, porém, apresentam caráter ativo e voluntário. Impressões intelectuais como a forma, a proporção e a durabilidade dos objetos são passivas e involuntárias, porque não há como deixar de percebê-las; no entanto, raciocínios, argumentos, lembranças e pensamentos em geral não são impressões totalmente involuntárias e passivas - ao contrário, essas afecções apresentam caráter ativo. As impressões intelectuais do tipo que regem as "leis e os costumes" ou "o aprendizado das artes" (HP I, 24) pedem uma postura ativa e voluntária. Essas impressões exigem do intelecto que desenvolva determinada atividade para compreender esse tipo de 
phainómenon. Em suma, nossas afecções sensíveis são sempre passivas, involuntárias e irrecusáveis, e nossas afecções intelectuais, embora muitas sejam delas também passivas e involuntárias, podem apresentar caráter ativo e voluntário.

Em numerosas passagens, Sexto Empírico parece identificar o páthos ou nossas afecções com o próprio phainómenon, pois o cético não recusa aquilo que nos leva ao assentimento de acordo com uma afecção passiva, e essas coisas são precisamente o que aparece (HP I, 19); ademais, "quando dizemos que o critério da persuasão cética é o que é aparente, implicitamente significamos por isso as aparências, pois elas dependem das nossas impressões passivas e involuntárias e não são objetos de questionamento" (HP I, 22). No entanto, embora nossas afecções sejam provocadas pelo que aparece, o que aparece [phainómenon] e nossas afecções [páthos] não são a mesma coisa. O que aparece causa em nós as afecções e, como efeito dessa impressão, temos a percepção do que aparece. A relação é de causa e efeito: da mesma forma que o efeito permite saber qual é sua causa, nós, através das afecções, também podemos ter a percepção do que aparece.

Em certo sentido, o que aparece realmente pode se confundir com nossas afecções, uma vez que para nós só é phainómenon aquilo que nos causa uma afecção, ou seja, aquilo que é em nós um páthos. Em outras palavras, o que aparece, aparece para algum sujeito; do contrário, não poderíamos dizer que seja algo que aparece. No entanto, já que causa e efeito não são a mesma coisa, não devemos tomar o phainómenon, que é um evento objetivo e a causa de outro evento que é subjetivo, por nossas próprias afecções, o páthos. O fato de termos impressões sensíveis e intelectuais nos permite falar de fenômenos sensíveis e fenômenos intelectuais. Os fenômenos sensíveis estão relacionados com as afecções dos sentidos e compartilham das mesmas características; já os fenômenos intelectuais estão ligados a nossas afecções intelectuais e também compartilham de suas mesmas características. Porém, os fenômenos não devem se confundir com nossas afecções.

Portanto, aquilo que aparece pode ser decomposto em fenômenos sensíveis e fenômenos intelectuais, assim como nossas afecções. Dessa forma, muitos fenômenos e muito daquilo que nos aparece se mostra involuntário, passivo e irrecusável; no entanto, parte daquilo que nos aparece exige de nós uma atitude ou uma postura racional voluntária. Não podemos classificar todos os fenômenos como tendo as mesmas características de passividade e involuntariedade, pois parte dos fenômenos intelectuais é caracterizada como uma espécie de atividade voluntária. Além disso, a noção de phainómenon ou o que aparece, mesmo tento um caráter objetivo, depende em alguma medida da noção subjetiva de páthos, pois somente 
através de nossas afecções, sejam elas sensíveis ou intelectuais, é que podemos perceber aquilo que aparece.

\section{A OBJETIVIDADE DO PHAINÓMENON E A SUBJETIVIDADE DA PHANTASÍA}

Nossa percepção do fenômeno é algo distinto do próprio fenômeno; por isso, devemos fazer uma distinção entre o que aparece e a aparência. Em geral, as mesmas frases que utilizamos para expressar o que aparece também são empregadas para expressar a aparência. Por essa razão, muitas vezes no próprio texto de Sexto Empírico é fácil confundir o phainómenon ou o que aparece com a phantasía, ou seja, a aparência daquilo que aparece (PORCHAT, 2013, p. 305-306). Não obstante, esses termos apresentam sentidos bastante distintos, já que o phainómenon é o que aparece e se manifesta fora de nós, e a phantasía é a aparência ou nossa percepção daquilo que aparece.

O phainómenon é o mundo objetivo que se mostra, se manifesta, se apresenta, e que aparece para nossa percepção. Notamos um mundo que é externo a nós; nesse sentido, ele se mostra para nossa percepção. O phainómenon ou o que aparece é exatamente isso: "é o que se mostra" (HP III, 266). Sendo assim, o que aparece é objetivo e externo a nós mesmos; além disso, o que é aparente "aparece para todos da mesma maneira" (HP III, 254, 266). Um objeto que se manifesta e aparece é independente de qualquer sujeito - independentemente de nossa vontade, o que aparece se mostra objetivamente. Devemos então distinguir aquilo que é phainómenon, objetivo e externo a nós, daquilo que é nossa percepção, ou seja, aparência em nós daquele phainómenon. É justamente a divisão subjetivo/objetivo que nos faz distinguir phainómenon e phantasía, pois, quando nos referimos à imagem mental que temos de algo, trata-se da aparência ou de nossa percepção daquela coisa, diferentemente da própria coisa que é o objeto de nossa percepção.

A phantasía ${ }^{8}$ é nossa percepção do fenômeno. Ela "é uma impressão na parte regente da mente" (HP II, 70) provocada por nossas afecções e, portanto, é uma percepção subjetiva daquilo que aparece. A aparência é o efeito em nós, é uma imagem ou percepção subjetiva daquilo que aparece e que é objetivo (PORCHAT, 2013, p. 307). O phainómenon, o que

\footnotetext{
${ }^{8}$ Como afirmado anteriormente, o termo phantasía foi comumente traduzido por "representação" (cf. a tradução de Bury). Neste trabalho, optamos por seguir a tradução de Annas e Barnes, que o traduz por "aparência". Essa opção marca melhor a distinção quanto ao termo phainómenon.
} 
aparece, é o evento externo e objetivo; a aparência ou phantasía é o evento interno e subjetivo causado por aquilo que aparece, é a percepção que o sujeito tem daquele evento objetivo. O phainómenon nos provoca um páthos, nossas afecções, e a partir dessas informações formamos a phantasía ou a percepção do que aparece. Inclusive, para alguns ${ }^{9}$ essa aparência reproduz fielmente o que aparece (HP II, 70; AM VII 371-373). Através do páthos ou de nossas afecções, formamos a aparência, que nos permite perceber o que aparece. Pelas impressões sensíveis, formamos a percepção ou aparência, em nossa mente, dos objetos físicos (HP II, 72). Através das impressões intelectuais temos a percepção ou aparência de fenômenos intelectuais, como conceitos, raciocínios, lembranças etc. A phantasía, portanto, é a aparência ou percepção que temos em nossa mente de um phainómenon que nos é externo e objetivo.

O objeto externo árvore é um evento do mundo, de modo que sua ocorrência é independente de qualquer sujeito. Digamos que o fenômeno árvore aparece para determinada pessoa; essa pessoa então o percebe, e em sua mente existe uma aparência da árvore. A aparência da árvore não é objetiva e nem externa ao sujeito; ao contrário, a percepção da árvore é subjetiva, interna, pessoal e dependente desse sujeito. A aparência da árvore é a percepção subjetiva do fenômeno objetivo árvore. Embora o que aparece, ou seja, a árvore, ocorra no mundo, a percepção desse fenômeno ou a aparência da árvore é um evento que ocorre na mente do sujeito que percebe aquele objeto. Inclusive, segundo o ceticismo, a aparência de um fenômeno não implica que o objeto - realmente, essencialmente - seja como ele aparece. Podemos dizer que o mel nos aparece doce, mas não podemos afirmar que ele seja em si mesmo doce (HP I, 20), pois é possível, como de fato acontece, que um mesmo objeto provoque aparências distintas em sujeitos distintos; o mesmo mel às vezes aparece amargo, dependendo do sujeito e das circunstâncias.

Outro ponto confuso entre o que aparece e a aparência é o fato de utilizarmos as mesmas frases para nos referirmos tanto ao phainómenon quanto à phantasía. Na maioria das vezes, a frase que usamos para expressar o que aparece é idêntica à frase que usamos para expressar sua aparência. Apenas por um elemento subjetivo é que distinguimos o que aparece de sua aparência. Usualmente, o elemento subjetivo da aparência não é citado, o que faz com que as frases que expressam tanto o que aparece quanto a aparência se tornem idênticas. A frase "há um livro na mesa" expressa um phainómenon ou algo que aparece; a frase que melhor expressa a aparência desse objeto seria "S percebe que há um livro na mesa". Ao subtrairmos o elemento subjetivo "S percebe que" da frase que expressa a aparência, o que sobra é a frase

\footnotetext{
${ }^{9}$ Os estoicos
} 
"há um livro na mesa", a mesma que utilizamos para expressar o que aparece. Ocorre geralmente que, em vez de dizer a frase "eu percebo que há um livro na mesa”, digo apenas "há um livro na mesa". Esta última frase pode ser usada tanto para indicar o evento objetivo que aparece quanto o evento subjetivo, ou seja, minha percepção daquilo que me aparece.

Muitas vezes, o mesmo objeto pode ser percebido de formas diferentes, porque pode haver aparências distintas para um mesmo fenômeno. Os modos de Enesidemo cumprem bem a tarefa de demonstrar essas ocorrências (HP I, 40; HP I, 79; HP I, 91; HP I, 100; HP I, 118; HP I, 124; HP I, 129; HP I, 135; HP I, 141; HP I, 145). Sujeitos distintos têm aparências distintas, o que pode acarretar diferenças e variações nas percepções de um mesmo fenômeno. Um objeto geralmente produz aparências semelhantes a sujeitos distintos; porém, isso não significa que todas as aparências ou percepções de um objeto devem ser sempre semelhantes.

O phainómenon é o mundo que aparece e, sendo assim, pode aparecer simultaneamente para várias pessoas, e várias pessoas podem ter uma aparência comum do mesmo fenômeno o que aparece é perceptível para todos (HP III, 254; AM XI, 240). Um objeto na sala aparece para todos aqueles que se encontram dentro dessa sala. O objeto em si não sofre mudanças nem alterações, é sempre único e imutável; entretanto, as aparências ou as percepções individuais daquele objeto podem também variar.

A phantasía é sempre pessoal e individual. A aparência é uma percepção subjetiva de algo que aparece. Embora o que aparece seja objetivo e sem alterações, as percepções de um fenômeno podem variar. É possível que "o mesmo objeto apareça dissimilar [...] não estamos aptos a decidir entre nossas próprias aparências e aquelas dos outros animais" (HP I, 59). As aparências são de mesmo número para quantos são os sujeitos que percebem o fenômeno. Se um objeto na sala é único e não se altera, as aparências ou percepções desse objeto podem ser muitas; cada pessoa na sala pode ter uma percepção distinta desse objeto. Para cada dez pessoas, temos dez aparências do mesmo objeto, aparências tais que podem ser todas semelhantes, mas podem também variar. Todos na sala podem ter uma aparência semelhante do objeto em questão; mesmo que cada indivíduo tenha sua própria aparência, ela pode ser semelhante às aparências dos demais. Por outro lado, é também possível que nem todos tenham uma aparência semelhante; é possível que alguém tenha uma aparência diferente do mesmo objeto. ${ }^{10}$ Assim,

\footnotetext{
${ }^{10}$ Os exemplos com cores são os mais ilustrativos. Mesmo que um objeto possa aparecer semelhante para todos num ambiente, como um livro verde, é possível que nem todos tenham uma percepção desse objeto como sendo verde, como no caso dos daltônicos. Desse modo, mesmo que um objeto (algo que aparece) não mude, as percepções (aparências) desse objeto podem ser distintas.
} 
mesmo que aquilo que aparece seja único, as aparências ou percepções deste fenômeno podem ser muitas e podem também apresentar diferenças e variações.

Os próprios modelos de argumentação cética nada mais são que um apelo às diferenças e variações das aparências. Mesmo que na maioria das vezes as aparências sejam semelhantes ao que aparece, isso não significa que todas as aparências - phantasías - sejam sempre idênticas e fiéis ao phainómenon (HP I, 49, 59, 78). O cético aposta no conflito das aparências, mas para ele não há nada a objetar ao que aparece, ou seja, ao fenômeno. O phainómenon é algo que se manifesta e é inquestionável, ao passo que as aparências daquilo que aparece apresentam semelhanças e dessemelhanças e, por isso, causam grande confusão.

O texto de Sexto Empírico, em muitas passagens, é ambíguo ao tratar do phainómenon e da phantasía (PORCHAT, 2013, p. 305-306). Sexto diz que os céticos "não negam aquilo que aparece [...] de acordo com uma aparência passiva" (HP I, 19), mas seguem os fenômenos ou "o que é aparente, implicitamente significando por isso as aparências" (HP I, 22). Nessas passagens, podemos entender que assentir aos fenômenos significa seguir as coisas mesmas que aparecem, mas significa também que os céticos seguem suas próprias aparências, suas percepções subjetivas daquilo que aparece. Há discussão sobre se o cético segue os fenômenos no sentido objetivo desse termo ou se segue somente sua própria percepção subjetiva das coisas que lhe aparecem.

O phainómenon nele mesmo, como vimos, é externo e objetivo, e a phantasía ou as percepções do fenômeno são sempre subjetivas e pessoais. $\mathrm{O}$ fenômeno ao qual o cético assente é objetivo, pois o cético assente àquilo que aparece comum e irrecusável para todos (HP III, 254; AM XI, 240); no entanto, se um fenômeno objetivo aparece para ele é porque o cético tem desse objeto uma percepção - uma phantasía. Só faz sentido dizer que segue um fenômeno se o cético tem desse fenômeno uma percepção subjetiva e pessoal. $O$ cético tem acesso ao fenômeno objetivo através das afecções [páthos] e da aparência [phantasía] que tem dele. De toda sorte, parece que, quando o cético diz seguir o phainómenon ou aquilo que aparece, ele não tem a intenção de dizer que assente exclusivamente às coisas objetivas que aparecem, mas que assente a sua própria percepção ou sua própria aparência do fenômeno. Quando diz que assente ao fenômeno, com isso quer dizer que assente àquele fenômeno que lhe aparece, do qual tem uma percepção, uma aparência. ${ }^{11}$

\footnotetext{
${ }^{11}$ Esse é um ponto bastante problemático no ceticismo pirrônico. Assentir aos fenômenos é implicitamente assumir uma postura extremamente internista? Ou o assentimento aos fenômenos indica aquilo que é objetivo e impessoal? Não estamos livres de contestação, mas temos forte inclinação para aceitar como resposta a segunda opção.
} 
Ao assentir ao phainómenon, o cético pode pretender assentir às coisas objetivas do mundo, ao fenômeno objetivo que aparece; porém, só é possível fazê-lo através das aparências subjetivas e pessoais. Somente através da aparência subjetiva é que podemos ter acesso ao fenômeno objetivo que aparece. Quando dizemos que "o critério cético da ação é o que aparece, implicitamente estamos significando as aparências, pois estas dependem das nossas afecções passivas e involuntárias" (HP I, 22). Em outras palavras, o assentimento dos céticos ao fenômeno objetivo é também um assentimento às suas próprias aparências, e não poderia ser de outro modo, pois é através de nossa própria aparência subjetiva que acessamos e percebemos o fenômeno objetivo que é externo a nós.

O phainómenon é algo a que podemos ter acesso, mas unicamente através da phantasía. Acessamos o que é aparente através de nossa percepção ou das aparências. Só acessamos um fenômeno $X$ do mundo quando temos dele uma percepção, ou seja, quando temos em nós a aparência de X. Essa é a condição da percepção humana; não há como percebermos os fenômenos de outra maneira. Percebemos um evento objetivo através da percepção subjetiva, em nossa mente, que temos desse evento. Quando o cético diz que assente ao fenômeno objetivo, implicitamente assente também a sua percepção subjetiva.

Pode-se objetar que, assim como não temos acesso às coisas em si mesmas, também não teríamos acesso ao próprio phainómenon, mas somente a nossa phantasía. As únicas coisas a que teríamos acesso seriam nossas próprias aparências subjetivas. Assim como não temos acesso ao Ser ou à natureza real das coisas, também não teríamos acesso ao phainómenon ou àquilo que aparece.

Certamente não temos um acesso direto ao phainómenon, mas apenas à aparência em nós dos fenômenos. Essa phantasía, no entanto, é causada em nós pelo próprio phainómenon. Assim, acessamos o fenômeno objetivo de modo indireto, por meio de nossas aparências subjetivas (HP I, 19, 22). Não temos acesso algum ao Ser das coisas porque ele não nos causa impressão alguma; não acessamos por meio algum a natureza real das coisas porque ela não causa em nós qualquer afecção ou páthos. A natureza real das coisas é pura conjectura dos filósofos dogmáticos. Por outro lado, aquilo que aparece [phainómenon] causa em nós uma afecção [páthos], provocando em nós uma aparência ou uma percepção [phantasía]. Para o ceticismo, é por meio dessas afecções e das aparências que temos acesso àquilo que aparece, ou seja, aos fenômenos. Assim, não dizemos que um fenômeno é tal como ele nos aparece. É possível que haja aparências distintas para o mesmo fenômeno; podemos dizer que os fenômenos nos aparecem de tal e tal maneira. 
O cético, ao dar assentimento aos fenômenos, não diz que as coisas são do modo como elas aparecem, e por isso não é dogmático. Ao fazer seu discurso, o cético está apenas reportando suas próprias percepções, está relatando suas próprias aparências, sem manter opinião nem qualquer afirmação sobre a natureza real das coisas (HP I, 15). Todavia, ao dizer as suas próprias aparências, o cético se refere ao fenômeno que as produziu; ele assente ao fenômeno objetivo que provoca essas aparências. Assim, o cético assente ao que aparece e faz dessas coisas seu critério prático de ação e de conduta, sem abrir mão da suspensão de juízo sobre as afirmações dogmáticas a respeito do que as coisas realmente são em si mesmas.

\section{CONSIDERAÇÕES FINAIS}

A proposta geral deste texto foi discutir e esclarecer a noção de phainómenon, principalmente sua relação com outro termo bastante relevante na compreensão do pirronismo, o conceito de phantasía. Vimos que o assentimento do cético aos fenômenos objetivos, em certa medida, é um assentimento a sua própria percepção subjetiva. Somente através da aparência [phantasía] percebemos o que aparece [phainómenon]. Em outras palavras, os fenômenos objetivos apresentam sempre uma característica subjetiva, que é o fato de aparecerem para alguém. Além disso, vimos que o assentimento cético aos fenômenos não é dogmático, porque não visa a essência ou a natureza real das coisas, mas apenas a relatar como as coisas nos aparecem. Dessa forma, uma vida cética guiada pelos fenômenos não seria nem dogmática nem inativa, visto que, para além da suspensão de juízo [epokhé], o cético é também aquele que assente ao phainómenon e faz desse assentimento seu critério de escolha e de ação. Assim, além da noção de suspensão de juízo, a noção de fenômeno se mostra como conceito fundamental para uma compreensão ampla do ceticismo pirrônico. 


\section{REFERÊNCIAS BIBLIOGRÁFICAS}

ANNAS, Julia; BARNES, Jonathan. The modes of scepticism. Cambridge: Cambridge University Press, 1985.

BETT, Richard. Scepticism and ethics. In: BETT, R. (Ed.) The Cambridge companion to ancient scepticism. Cambridge: Cambridge University Press, 2010. p. 181-194.

BOLZANI FILHO, Roberto. Acadêmicos versus pirrônicos. Sképsis, São Paulo, n. 7, 2011. p. 5-55.

O ceticismo pirrônico na obra de Sexto Empírico. 76f. Dissertação de mestrado, USP, 1992.

BROCHARD, Victor. Os céticos gregos. Trad. Jaimir Conte. São Paulo: Odysseus, 2008.

BURNYEAT, Myles F. Pode o cético viver seu ceticismo? Trad. Rodrigo Pinto de Brito. Sképsis, São Paulo, n. 5, 2010, p. 201-239.

FREDE, Michael. As crenças do cético. Sképsis, São Paulo, n. 3, 2008, p. 139-168.

GAZZINELLI, Gabriela. A vida cética de Pirro. São Paulo: Edições Loyola, 2009.

HUME, David. Investigações sobre o entendimento humano. Trad. José Oscar de Almeida Marques. São Paulo: Editora Unesp, 1999.

LANDESMAN, Charles. Ceticismo. Trad. Cecília Bartalloti. São Paulo: Loyola, 2002.

LEE, Mi-Kyoung. Antecedents in early Greek philosophy. In: BETT, R. (Ed.) The Cambridge companion to ancient scepticism. Cambridge: Cambridge University Press, 2010. P. 13-35.

PATRICK, Mary Mills. Sexto Empírico e o ceticismo grego. Trad. Jaimir Conte. Florianópolis, 2010.

PERIN, Casey. Scepticism and belief. In: BETT, R. (Ed.) The Cambridge companion to ancient scepticism. Cambridge: Cambridge University Press, 2010. p. 145-164.

The demand of reason: an essay on Pyrrhonian scepticism. Oxford: Oxford University Press, 2010.

PLATÃO. Teeteto. Trad. Carlos Alberto Nunes. Belém: Editora Universitária UFPA, 2001.

PORCHAT PEREIRA, Oswaldo. A noção de phainómenon em Sexto Empírico. Analytica, Rio de Janeiro, v. 17, n. 2, 2013, p. 291-323. 
117-145.

. Sobre o que aparece. In: Rumo ao ceticismo. São Paulo: Editora Unesp, 2006. p.

SEXTUS Empiricus. Against the logicians. Trad. R. G. Bury. Harvard: The Loeb Classical Library, v. II, 2006.

_. Against the phycisists and Against the ethicists. Trad. R. G. Bury. Harvard: The Loeb Classical Library, v. III, 2006.

Against the professors. Trad. R. G. Bury. Harvard: The Loeb Classical Library, v. IV, 2006.

. Outlines of skepticism. Ed. revista. Trad. Julia Annas e Jonathan Barnes. Cambridge: Cambridge University Press, 2000.

VOGT, M. Katja. Scepticism and action. In: BETT, R. (Ed.) The Cambridge companion to ancient scepticism. Cambridge: Cambridge University Press, 2010. p. 165-180. 